\title{
An Unusual Angiosarcoma
}

\section{A Case Report}

\author{
M.K. Al-Meshan a K.C. Katchy ${ }^{\mathrm{b}}$ \\ Departments of a Surgery and ${ }^{\mathrm{b} P a t h o l o g y, ~ A l-S a b a h ~ H o s p i t a l, ~ S a f a t, ~ K u w a i t ~}$
}

\section{Key Words}

Angiosarcoma $\cdot$ Retroperitoneum · Survival · Disease-free period

\begin{abstract}
Objective: To document a retroperitoneal angiosarcoma with a 12-year disease-free period. Clinical Presentation and Intervention: A 50-year-old farmer was referred to the Urology Clinic, Al-Sabah Hospital, Kuwait, with a 1year history of recurrent left renal colic. Radiological investigations revealed 2 renal cysts at the lower pole and an extrarenal soft tissue mass, presumably of adrenal origin, at the upper pole. Laparotomy confirmed both the renal cysts and a circumscribed soft tissue mass. The latter was separate from the adrenal gland but had a vascular connection with an adrenal vessel. Pathological examination showed an encapsulated angiosarcoma. The patient did not have any adjuvant therapy after surgery but was followed up with annual radiological investigations for 12 years. No evidence of recurrence or metastasis was seen. Conclusion: The 12-year diseasefree period in this case is exceptional for angiosarcomas, which is a high-grade sarcoma.
\end{abstract}

Copyright $@ 2004$ S. Karger AG, Basel

\section{Introduction}

Angiosarcomas are rare, highly aggressive vascular tumors, whose clinical course is marked by local recurrence, metastasis and a high mortality rate. They are mostly located in the skin and superficial soft tissue and are usually managed by a combination of surgery and adjuvant therapy. Their average 5-year survival is about $10 \%$ [1].

We report a case of retroperitoneal angiosarcoma diagnosed in 1988 in Kuwait, followed up with an annual radiological examination for a period of 12 years during which the patient was disease free, before he was lost to follow-up.

\section{Case Report}

A 50-year-old male farmer was referred in August 1988 to the Urology Clinic, Al-Sabah Hospital, Kuwait, with a 1-year history of recurrent left renal colic. For about 18 weeks prior to the referral, the colic had increased in both intensity and frequency. There was no past history of radiation therapy, chemotherapy or trauma to the abdomen. Physical examination at the clinic was unremarkable. He had a blood pressure of $140 / 90$ and a regular pulse of 85 beats/min. Routine laboratory investigations were within normal limits.

Plain abdominal X-ray and ultrasonography revealed a calcified cyst at the lower pole of the left kidney. Hydatid disease was suspected but excluded by a negative indirect hemagglutination test. Subsequently, an intravenous pyelogram confirmed the presence of a calcified renal cyst. Also it showed a lateral displacement of the left

\begin{tabular}{ll}
\hline KARGER & ( ) 2004 S. Karger AG, Basel \\
Fax +4161306 1234 & 1011-7571/04/0135-0295\$21.00/0 \\
$\begin{array}{l}\text { E-Mail karger@karger.ch } \\
\text { www.karger.com }\end{array}$ & $\begin{array}{l}\text { Accessible online at: } \\
\text { www.karger.com/mpp }\end{array}$
\end{tabular}

Mohammed Khalid Al-Meshan, MD

Department of Surgery, Al-Sabah Hospital

PO Box 3360

Safat 13034 (Kuwait)

Tel. +965 483 2077, Fax +965 483 6201, E-Mail Dram40@hotmail.com 


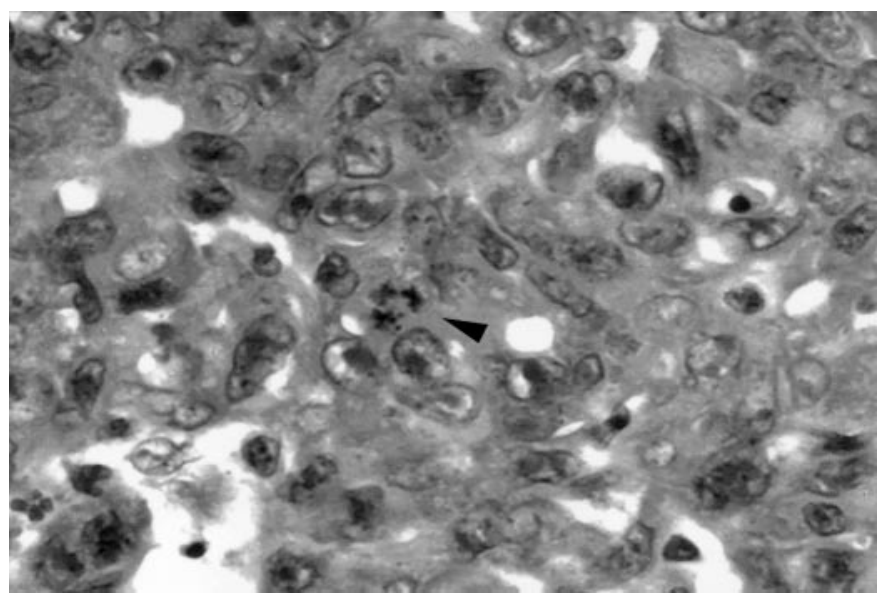

Fig. 1. Atypical epithelioid cells arranged in compact formation. Abnormal mitotic figure (arrowhead) is present. HE. $\times 400$.

kidney by a soft tissue mass at the upper pole. The mass was suspected to be adrenal in origin. However, a computerized tomography (CT) scan revealed that the mass appeared separate from the diaphragm and the left kidney. In addition, 2 cysts were observed in the left kidney. One was small, densely calcified and situated posterolaterally, while the other was large and located posteromedially.

As a result of these findings, a laparotomy was performed.

At surgery, it was observed that about two thirds of the left renal parenchyma had been replaced by a bilocular cyst containing thick muddy yellow brown material. The left adrenal gland was in situ but enlarged by a fresh blood clot. An ipsilateral encapsulated, firm mass measuring about $9 \times 6 \mathrm{~cm}$ was found on the anteromedial surface of the psoas major muscle. The mass was separated from both the adrenal gland and the kidney. A blood vessel of small caliber was observed leaving the mass at its inferomedial surface and joining one of the adrenal vessels. A left total nephrectomy with adrenalectomy was carried out. The retroperitoneal mass was carefully dissected out and completely excised.

Pathological examination of the left kidney showed patchy interstitial chronic inflammatory cell infiltrate and 2 thick-walled cysts that contained organizing blood clots. There was no epithelial lining, and the wall was mostly fibrosed with hemosiderin-laden macrophages, chronic inflammatory cells and strips of smooth muscle. The left adrenal gland was normal. The retroperitoneal mass grossly consisted of an ovoid, evenly contoured mass weighing 500 $\mathrm{g}$ and measuring $7 \times 5 \mathrm{~cm}$. Sectioning revealed an apparently encapsulated pinkish red fleshy mass with a yellow soft center. Microscopically, the tumor showed atypical spindle, histiocytoid or epithelioid cells either lining vascular channels or arranged in solid and papillary patterns (fig. 1). There were mitotic figures, necrosis and extensive hemorrhage. Fibrosis, calcification, chronic inflammatory cells and hemosiderin pigment marked the periphery of the tumor (fig. 2).

Immunoperoxidase stains done at the Armed Forces Institute of Pathology, Washington, D.C., USA, showed that the tumor cells stained positively for CD31 and factor-VIII-related antigen, but negatively for CD68, HMB 45 and cytokeratin.

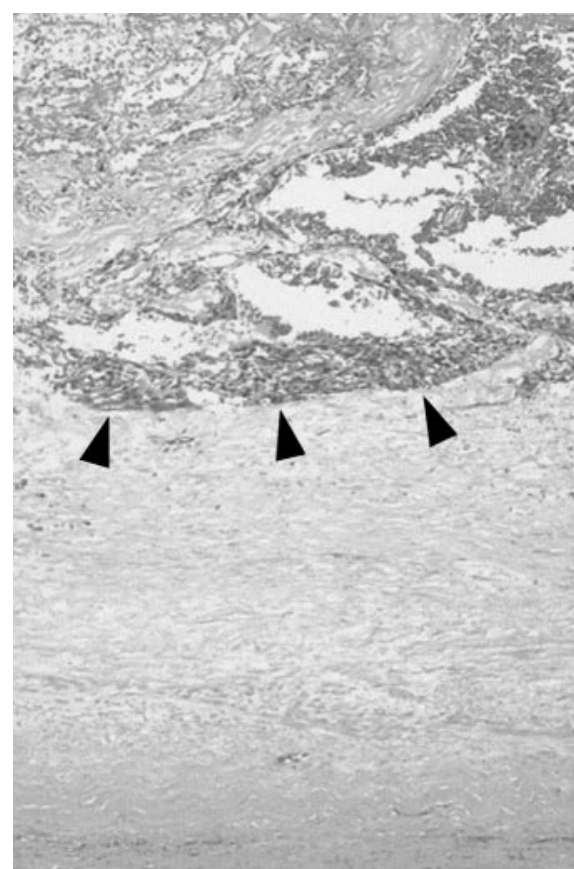

Fig. 2. Vasoformative tumor with a thick fibrous capsule. Arrowheads indicate pushing border of the tumor.

The unusual benign clinical course prompted external review of the slides which were sent to the Department of Pathology, Brigham and Women's Hospital, Boston, Mass., and the Armed Forces Institute of Pathology, Washington, D.C., USA. The first reviewer made a diagnosis of a high-grade angiosarcoma, while the second reported it as consistent with angiosarcoma.

The postoperative course was uneventful. Although the pathology report indicated that the retroperitoneal mass was an angiosarcoma, no further therapy was administered. The patient was discharged home after 10 days but monitored annually by routine laboratory investigation, chest X-ray and abdominal CT scan. As at the last visit in August 2001, he was healthy and free of tumor.

\section{Discussion}

The angiosarcoma in this case report is unique for its clinical course, location and encapsulation. The 12-year disease-free period documented in this case was extremely unusual for an angiosarcoma [2].

In a review of 80 soft tissue angiosarcomas, MeisKindblom and Kindblom [3] listed tumor location in the peritoneum and large tumor size as poor prognostic factors. Both factors were present in this case. Similarly, Karpeh et al. [4] have suggested that complete excision of all gross disease and absence of metastasis at presentation 
favorably influence the survival period in angiosarcomas. It is conceivable that encapsulation facilitated a complete excision of this tumor and may be a major contributory factor to the benign course of the disease in this case even in the presence of poor prognostic factors. Despite the long survival, the possibility of a borderline vascular tumor was rejected because of the histological features of necrosis, pleomorphism and mitosis.

Encapsulation of this tumor is unusual for an angiosarcoma, which typically has infiltrative margins. The vascular connection between the tumor and an adrenal vessel may suggest an origin within a preexisting structure. This would have explained its encapsulation. However, search for an accessory adrenal gland or an aneurysm was unrevealing. Also, there was no history of a previous trauma or hematological disorder to suggest a preexisting hematoma. Consequently, its origin remains speculative.

Angiosarcomas are rare in the retroperitoneum where its incidence as reported in the literature varies from 0 to
6\% [4-7] The large size of the present tumor and its discovery as an incidental finding are consistent with most retroperitoneal tumors [8].

\section{Conclusion}

This case report serves as a reminder that histologically malignant tumors may - on rare occasions - run an unexpected benign clinical course.

\section{Acknowledgement}

We wish to thank Prof. Christopher D.M. Fletcher of the Department of Pathology, Brigham and Women's Hospital, Boston, Mass., and Julie C. Fanburg-Smith of the Department of Soft Tissue Pathology, Armed Forces Institute of Pathology, Washington, D.C., USA, for the external slide review.

\section{References}

1 Fletcher CDM: Vascular tumors: An update with emphasis on the diagnosis of angiosarcoma and borderline vascular neoplasm. Monogr Pathol 1996;38:181-206.

2 Holden CA, Spittle MF, Jones EW: Angiosarcoma of the face and scalp: Prognosis and treatment. Cancer 1987;59:1046-1057.

3 Meis-Kindblom JM, Kindblom LG: Angiosarcoma of soft tissue: A study of 80 cases. Am J Surg Pathol 1998;22:683-697.
4 Karpeh MS Jr, Caldwell C, Gaynor JJ, Hajdu SI, Brennan MF: Vascular soft tissue sarcoma: An analysis of tumor related mortality. Arch Surg 1991;126:1474-1481.

5 Kilkenny JW 3rd, Bland KI, Copeland EM 3rd: Retroperitoneal sarcoma: The University of Florida Experience. J Am Coll Surg 1996;182: 329-339.

6 Mark RJ, Poen JC, Tran LM, Fu YS, Juillard GF: Angiosarcoma. A report of 67 patients and review of literature. Cancer 1996;77:24002406.
7 Naka N, Ohsawa M, Tomita Y, Kanno H, Uchida A, Aozasa K: Angiosarcoma in Japan: A review of 99 cases. Cancer 1996;75:989996.

8 Ziran BH, Makley JT, Carter JR: Primary retroperitoneal sarcomas: Common diagnoses, uncommon disease. Clin Orthop 1996;331: 277-282. 